\title{
Mobilitas Pedagang Buah Dan Sayur Di Pasar Anyar Singaraja
}

\author{
Made Gunawan ${ }^{1}$, I Made Sarmita², Putu Indra Christiawan ${ }^{3}$ \\ ${ }^{123}$ Jurusan Pendidikan Geografi \\ FIS Universitas Pendidikan Gansha \\ Singraja, Indonesia
}

e-mail: madegunawan121@gmail.com, indra.christiawan@undiksha.ac.id, made.sarmita@undiksha.ac.id

\begin{abstract}
Abstrak
Penelitian ini bertujuan untuk mengetahui (1) frekuensi mobilitas pedagang buah di Pasar Anyar Singaraja (2) pendapatan pedagang buah di Pasar Anyar Singaraja (3) Hubungan frekuensi mobilitas dan pendapatan pedagang buah di Pasar Anyar Singaraja. Penelitian ini menggunakan pendekatan penelitian deskriptif kuantitatif. Subjek penelitian ini adalah Pedagang Buah pasar Ayar Singaraja. Teknik pengumpulan data dalam penelitian menggunakan : (1) observasi (2) wawancara (3) pencatatan dokumen. Teknik analisis data ini dilakukan melalui analisis deskriptif kuantitatif. Hasil penelitian menunjukan bahwa (1) Rata - rata dalam seminggu frekuensi mobilitas yang dilakukan mencapai 6,4 kali dalam seminggu (2) Penghasilan Bersih terendah pelaku mobilitas adalah Rp. 100.000 dan tertinggi Rp. 500.000 dalam 1 kali berdagang (3) Frekuensi mobilitas pedagang buah dan sayur Pasar Anyar Singaraja tidak berhubungan dengan tingkat pendapatan pedagang buah dan sayur Anyar Singaraja karena harga rtabel $(0,335)$ lebih besar daripada rhitung sebesar $(0,150)$.
\end{abstract}

Kata Kunci : frekuensi mobilitas dan pendapatan

\begin{abstract}
This study aims to determine (1) the frequency of mobility Anyar market fruit vendors, Singaraja (2) income Anyar market fruit vendors, Singaraja (3) frequency relationship mobility and income Anyar Singaraja fruit merchant market. This research uses descriptive quantitative research approaches. The subjects were Wholesalers Fruit Anyar market Singaraja. Data collection techniques in research using: (1) Observation (2) interviews (3) the listing document. Data analysis technique is done through quantitative descriptive analysis. The results showed that (1) Average - Average week mobility do frequency from 6.4 times a week (2) Net Income mobility is lowest offender Rp. Highest 100,000 and Rp. 500,000 in the first time to trade (3) Frequency mobility vendors of fruits and vegetables Anyar
\end{abstract}


Market Singaraja not related to income level traders of fruit and vegetables Anyar Market Singaraja because rtabel price $(0,335)$ larger than rhitung of $(0.150)$.

keyword : frequency mobility and earnings

\section{PENDAHULUAN}

Migrasi sebagai bagian dari mobilitas penduduk horizontal adalah salah satu komponen pertumbuhan penduduk selain fertilitas dan mortalitas. Ketiga komponen ini merupakan peristiwa kependudukan yang selalu akan terjadi dan tetap menarik, tergantung dari aspek mana kajian itu dilakukan (Kasto, 2002). Saat ini untuk Indonesia, pembahasan migrasi secara regional mempunyai arti yang sangat penting mengingat adanya densitas dan distribusi penduduk yang masih tidak merata, adanya faktor-faktor pendorong dan penarik untuk melakukan migrasi, adanya desentralisasi dalam pembangunan dan di pihak lain komunikasi dan transportasi semakin lancar (Munir, 2007).

Kurangnya kesempatan kerja di bidang pertanian, non pertanian, terbatasnya fasilitas pendidikan yang ada, dan yang utama adalah kesempatan mendapat pendapatan yang lebih tinggi menjadi faktor pendorong penduduk untuk meninggalkan daerah asalnya dan melakukan migrasi ke kota-kota besar (kekuatan sentrifugal). Namun di samping kekuatan sentrifugal tersebut ada pula kekuatan sentripetalnya yaitu faktor yang mengikat penduduk di daerah asalnya seperti, eratnya hubungan kekerabatan karena banyak keluarga dekat, faktor kenyamanan di daerah asal karena sistem gotong royong yang kuat, tanah pertanian yang dimiliki tidak bisa ditinggalkan, dan terakhir penduduk itu sendiri yang sangat terikat pada daerah kelahirannya.

Kedua kekuatan di atas yakni kekuatan sentrifugal dan kekuatan sentripetal jelas saling bertentangan. Penduduk dihadapkan pada dua pilihan berat, apakah tetap tinggal di daerah asal dengan keadaan ekonomi dan fasilitas pendidikan yang terbatas atau berpindah ke daerah lain dengan meninggalkan sawah atau ladang yang dimiliki. Untuk mengatasi problem tersebut, diambil suatu kompromi yaitu mengadakan mobilitas penduduk nonpermanen atau migrasi sirkuler (Mantra, 2000).

Pembahasan tentang migrasi sirkuler semakin menarik untuk dilakukan. Dari beberapa bentuk mobilitas yang ada, yang paling banyak terjadi adalah mobilitas penduduk sirkuler (nonpermanen). Mobilitas ini mengandung makna tingginya keterikatan penduduk dengan daerah asal. Dengan adanya peningkatan sarana transportasi dan informasi, jangkauan mobilitas penduduk atau migrasi sirkuler semakin jauh dan waktu yang ditempuh semakin singkat. Pelaku mobilitas ini (migran sirkuler) akan mencari pekerjaan di wilayah mana pun selama di wilayah tersebut dia mendapatkan upah yang tinggi (Kasto, 2002). Penelitian ini mengkhususkan kajiannya terhadap migrasi sirkuler yang dilakukan oleh pedagang buah dan sayur di Pasar Tingkat Kota Singaraja dengan fokus kajian mengenai frekuensi mobilitas yang dilakukan dikaitkan 
dengan tingkat pendapatan yang diperoleh. $\mathrm{Hal}$ ini penting dibahas mengigat bervariasinya karakteristik penduduk sehingga tingkat mobilitas yang dilakuakan juga dipandang akan bervariasi. Sampai sat ini pembahasan yang mengulas tentang hal ini masih minim dan perlu dikaji lebih lanjut.

Kabupaten Buleleng adalah kabupaten yang terletak di Provinsi Bali bagian utara. Kabupaten Buleleng merupakan salah satu kabupaten yang sebagian besar penduduknya masih bergerak di bidang pertanian, masyarakat yang bekerja sebagai petani ada yang langsung memasarkan hasil pertaniannya ke berbagai daerah. Secara umum, manusia cenderung terkonsentrasi pada daerah-daerah yang memiliki sarana dan prasarana yang mendukung. Pasar merupakan salah satu contoh realita sarana dan prasarana yang mempengaruhi konsentrasi penduduk. Fungsi pasar yang kompleks cenderung akan membentuk siklus perekonomian yang berdampak pada manusia. Perkembangan siklus ekonomi akan membentuk suatu interaksi yang pada akhirnya membentuk suatu komunitas pedagang. Salah satu tempat yang menjadi tujuan para petani yang memasarkan hasil pertaniannya di Kabupaten Buleleng adalah Pasar Anyar yang berada di Kota Singaraja yang menjadi salah satu pasar induk yang ada di Kota Singaraja sehingga banyak petani, pengepul serta pengusaha yang memanfaatkan Pasar Anyar sebagai tempat transaksi jual beli serta untuk menyalurkan hasil pertanian dari petani yang berdomisili di Kabupaten Buleleng maupun di luar Kabupaten Buleleng. Kebanyakan dari mereka yang berdagang di Pasar Anyar tidak menetap di
Singaraja melainkan mereka memiliki siklus harian atau pola sirkulasi dari daerah asal menuju ke Pasar Anyar maupun sebaliknya. Hal ini dilakukan oleh pedagang bertujuan untuk kembali beraktivitas di daerah asal guna bersosialisasi dan bekerja sesuai dengan pekerjaan masing-masing. Mereka yang melakukan kegiatan ini dapat digolongkan kedalam pelaku mobilitas sirkuler.

Alasan ekonomi selalu menjadi motif utama individu untuk melakukan mobilitas dari desa ke kota. Ini dilatar belakangi oleh terbatasnya lapangan pekerjaan di daerah asal. Disisi lain tanggung jawab seseorang untuk menghidupi keluarganya mendorong semangat kerja untuk dapat memenuhi kebutuhan keluarga sehingga minat para pedagang utuk menjual hasil produksinya ke Pasar Anyar Singaraja.

Data mengenai jumlah pelaku mobilitas pedagang Pasar Anyar sangat minim bahkan tidak ada instansi terkait yang menangani masalah ini, mengigat data ini sangat penting untuk mengetahui pembangunan di dalam sektor ekonomi dan pembangunan Kota Singaraja secara umum maka pengkajian lebih lanjut tentang mobilitas pedagang buah dan sayur di Pasar Anyar sangat menarik untuk dikaji dalam suatu penelitian dengan judul "Mobilitas Pedagang Buah dan Sayur di Pasar Anyar, Singaraja“.

Tujuan Penelitian Untuk menganalisis mendeskripsikan frekuensi mobilitas pedagang buah dan sayur di Pasar Anyar Singaraja yaitu Untuk mengidentifikasi tingkat pendapatan 
pedagang buah dan sayur di Pasar Anyar

Singaraja, untuk mengidentifikasi hubungan antara frekuensi mobilitas dengan tingkat pendapatan pedagang buah dan sayur di Pasar Anyar Singaraja.

\section{METODE}

Rancangan penelitian yang digunakan dalam penelitian ini adalah rancangan deskriptif dan korelasi yaitu pengumpulan data dan informasi untuk memberikan gambaran atau penegasan suatu konsep atau gejala dan menjawab pertanyaan - pertanyaan Suharsini (1990:130) menyatakan bahwa penelitian deskriptif ini mengambarkan apa adanya tentang suatu variabel, gejala atau keadaan. Hal yang dideskripsikan adalah frekuensi mobilitas dan pendapatan pedagang buah. Untuk melihat hubungan antara frekuensi mobilitas dengan pendapatan yang dilakukan pedagang buah yang ada di Pasar Tingkat Singaraja juga menggunakan rancangan deskriptif dengan analisis korelasional yaitu melihat keterkaitan antara dua variabel yang didasari oleh teori - teori yang terkait sebagai landasannya.

Data yang dikumpulkan dalam penelitian ini dari data primer dan data skunder a) Data primer, Data primer yang dibutuhkan meliputi : frekuensi mobilitas dan pendapatan pedagang buah dan sayur di Pasar Anyar, Singaraja. b) Data sekunder, Data primer yang dibutuhkan meliputi : fisiografis dan demografis Kecamatan Buleleng.

Berdasarkan jenis data diatas, maka beberapa teknik pengumpulan data yang digunakan adalah sebagai berikut : 1)
Observasi, Pengamatan dengan panca indra mengenai aktivitas pedagang buah dan sayur di Pasar Anyar Singaraja. Alat yang digunakan dalam observasi ini adalah lembar observasi. 2) Wawancara terstruktur, Penggalian informasi dari subjek peleitian terkait dengan data - data yang dibutuhkan yang mencakup frekuensi mobilitasnya dan tingkat pendapatan yang diperoleh. Alat bantu yang digunakan dalam metode ini adalah kuesioner. 3) Pencatatan dokumen, Metode ini adalah kegiatan mengumpulkan data yang tersimpan di lembaga/instansi, baik pemerintah maupun swasta. Data tersebut berupa data fisiografis letak astronomis, letak geografis, topografi, keadaan geologi, macam tanah, suhu,curah hujan, keadaan air, dan penggunaan lahan serta data demografis (jumlah penduduk dan komposisi penduduk). 4) Dokumentasi, Metode ini digunakan untuk merekam kegiatan berupa foto - foto kegiatan penelitian.

Data yang terkumpul selanjutnya dianalisis agar menjadi informasi yang bermakna terkait dengan masalah yang diteliti. Teknik analisis data yang digunakan dalam penelitian ini yaitu Permasalahan pertama dan kedua terkait dengan frekuensi mobilitas dan pendapatan pedagang buah dan sayur di Pasar Anyar, Singaraja dianalisis menggunakan teknik analisis deskriptif kuantitatif berupa distribusi frekuensi, persentase, mean. Permasalahan ketiga terkait hubungan frekuensi mobilitas dengan pendapatan. Melihat data yang akan dianalisis merupakan data yang berskala rasio maka teknik analisis yang digunakan adalah analisis statistik product moment. Analisis statistik product moment digunakan untuk mengetahui hubungan antara 
dua variable, yaitu frekuensi mobilitas dan tingkat pendapatan.

\section{HASIL DAN PEMBAHASAN}

Dalam penyajian hasil penelitian ini akan dipaparkan mengenai gambaran umum wilayah penelitian dan penyajian data hasil penelitian dari responden: Gambaran umum daerah penelitian akan ditinjau dari dua aspek, yaitu aspek lingkungan fisik dan lingkungan manusia. Uraian kedua aspek ini dimaksudkan untuk mengetahui bagaimana karakteristik daerah penelitian, karena lingkungan fisik dan manusia menunjukkan satu kesatuan yang menjadi suatu daerah memiliki karakteristik. Singaraja merupakan Ibu Kota dari Kabupaten Buleleng, yang menjadi bagian dari wilayah Provinsi Bali. Secara astronomis wilayah Kota Singaraja terletak pada $08^{\circ} 03^{\prime} 40^{\prime \prime} \mathrm{LS}-08^{\circ} 23^{\prime} 30^{\prime \prime}$ LS dan $115^{\circ} \quad 2^{\prime} \quad 55^{\prime \prime} B T-115^{\circ} \quad 27^{\prime} \quad 28^{\prime \prime}$ BT (BAPPEDA Kabupaten Buleleng, 2017). wilayah perkotaan Singaraja meliputi 22 desa/kelurahan yang berada pada 2 kecamatan yaitu Kecamatan yaitu Kecamatan Buleleng dan sebagian Kecamatan Sukasada dengan luas total $39,13 \mathrm{Km}^{2}$. Namun demikian, secara fungsional Kota Singaraja mempunyai luas $32,59 \mathrm{Km}^{2}$ (BAPPEDA Kabupaten Buleleng, 2017). Batuan yang menyusun wilayah Kota Singaraja didominasi oleh hasil gunung berapi yang berumur kwarter yang terdiri dari : tufa dan endapan lahar hujan Beratan Purba dan Batur Purba (Qbb). Serta batuan yang menyusun pada wilayah Kelurahan Penarukan adalah hasil gunung berapi yang berumur Pliosen-Resen, dari tua ke muda yaitu : Formasi Asah (Tpva), terdiri dari lava $(\mathrm{Pa})$ breksi gunung api $(\mathrm{Pa})$ dan tufa batu apung $(\mathrm{Pa})$, bersisipan batuan sedimen gampingan
(BAPPEDA Kabupaten Buleleng,2017). Jumlah dan persebaran penduduk di Kota Singaraja sangatlah bervariasi pada desa/ kelurahan. Umumnya pada daearah dengan luas yan lebih besar akan dihuni oleh penduduk yang lebih banyak. Kota Singaraja sebagai ibu kota Kabupaten Buleleng tentu dilengkapi dengan fasilitas -fasilitas umum yang memadai seperti jalan, pasar, pertokoan, sekolah, sarana kesehatan, fasilitas rekreasi dan lain sebagainya. Hal tersebut merupakan faktor penarik yang dimiliki oleh Kota Singaraja yang menyebabkan banyak menyerap tenaga kerja dari wilayah lain untuk datang ke Kota Singaraja. Penduduk yang datang akan semakin besar dan bervariasi, baik dalam karakter dan adat istiadat. Jumlah penduduk yang besar juga berpengaruh terhadap perluasan kota. Jenis pekerjaan yang banyak di tekuni di Kota Singaraja adalah pada sektor perdagangan yang pada tahun 2018 mencapai 11.418 jiwa penduduk berkecimpung dalam sektor ini. Tingginya sektor perdagangan yang menjadi mata pencarian penduduk Kota Singaraja tidak terlepas dari banyaknya daearah-daearah pertokoan dan juga rendahnya tingkat pendididkan hal ini terlihat dari jumlah penduduk yang memiliki pendidikan rendah tidak mampu memasuki pekerjaan di sektor formal seperti menjadi pedagang buah dan sayur di Pasar Anyar Singaraja. Selain itu, Kota Singaraja meruakan ibu kota dari Kabupaten Buleleng yang menjadi pusat aktivitas sosial, ekonomi dan pemerintahan.

Karakteristik Pedagang Buah dan Sayur Pelaku Mobilitas berkenaan dengan keadaan individu selaku pelaku mobilitas di Pasar Anyar Singaraja. Karakteristik ini 
berkenaan dengan umur, jenis kelamin, status, dan tingkat pendidikan.

Jarak merupakan salah satu faktor yang menjadi pertimbangan individu dalam melakukan kegiatan mobilitas. Jarak mobilitas merupakan jarak antara tempat tinggal atau daerah asal dengan daerah tujuan atau Pasar Anyar Singaraja dengan daerah tujuan jarak tersebut dapat dihitung dalam satuan kilometer $(\mathrm{Km})$.

Tingkat Pendapatan Kotor dan Bersih Pedagang Buah dan Sayur Pelaku Mobilitas di Pasar Anyar Singaraja, berdasarkan hasil pengumpulan data di lapangan maka diperoleh hasil tabulasi data mengenai pendapatan responden dalam melakukan aktivitas mobilitas dalam waktu 1 (satu) minggu. Dari tabulasi tersebut dapat diketahui bahwa penghasilan bersih terendah pelaku mobilitas adalah $\mathrm{Rp}$. 100.000 dan tertinggi Rp. 500.000 dalam 1 kali berdagang. Berikut disajikan pendapatan para pelaku mobilitas. pendapatan para pelaku mobilitas di Pasar Anyar Singaraja ditinjau dari UMR yang berlaku di akhir 2018 yaitu 2.165.000,00 per orang dalam 1 bulan rata-rata memiliki penghasilan bersih diatas UMR Kabupaten Buleleng dengan demikian taraf hidup pedagang sudah masuk dalam katogori hidup layak.

Persebaran daearah asal pedagang buah dan sayur di Pasar Anyar Singaraja yang dimaksud dalam penelitian ini adalah persebran daearah asal pelaku mobilitas yaitu lokasi tempat tinggal pelaku mobilitas. Berdasarkan hasil penyebaran kuesioner para pelaku mobilitas tersebar di 17 desa dari 3 kecamatan di Kabupaten Buleleng. Jadi berdasarkan hasil SPSSS yaitu hasil koefisien korelasinya signifikan (dapat digeneralisasikan) atau tidak, maka dapat dibandingkan dengan $r$ tabel dengan taraf kesalahan tertentu. Memperhatikan $r$ tabel product moment dengan kesalahan 5\% (tarap kepercayaan 95\%) dan $\mathrm{N}=40$, maka harga tabel $=0,312$ (sugiyono 2010:373). Ternyata harga $r$ hitung $(0,150)$ lebih besar dibandingkan $r$ tabel $(0,355)$, sehingga Ho ditolak dan Ha diterima.

Jadi frekuensi mobilitas harian pedagang buah dan sayur di Pasar Anyar Singaraja tidak berhubungan dengan tingkat pendapatan pedagang buah dan sayur Pasar Anyar Singaraja karena harga $r_{\text {tabel }}(0,355)$ lebih besar dari pada rhitung sebesar $(0,150)$.

Korelasi Frekuensi Mobilitas dengan Tingkat Pendapatan. nilai $r$ hitung adalah sebesar 0,150 . Di sisi lain nilai $r_{\text {tabel }}$ yang digunakan (taraf signifikansi $5 \%, N=40$ ) adalah sebesar 0,355. Dengan demikian $r$ hitung lebih kecil dari $r$ tabel sehingga dapat dinyatakan bahwa antara frekuensi mobilitas dengan tingkat pendapat tidak terdapat hubungan yang signifikan. Walaupun tidak terdapat hubungan yang signifikan, dengan melihat nilai $r$ hitung adalah lebih mengarah kepada hubungan yang negatif. Terkait dengan hipotesis yang diajukan maka, Ha ditolak, Ho diterima. Dengan demikian frekuensi mobilitas tidak terdapat hubungan terhadap tingkat pendapatan para pedagang buah dan sayur di Pasar Anyar Singaraja. Dikarenakan karakteristik dari responden atau pedagang buah dan sayur Pasar Anyar Singaraja memiliki fariasi pada tingkat mobilitas dalam satu minggu walaupun tingkat pendapatan dari pedagang memiliki pendapatan yang tinggi maupun rendah, kegiatan mobilitas tetap 
dilakukan kemungkinan terdapat faktor lain yang mempengaruhi yang menjadi belum diteliti dalam penelitian ini serta faktor penentu dan pembeda fekuensi mobilitas para responden misalnya, jarak dan sarana dan prasarana transportasi yang memadai.

Persebaran daerah asal pedagang buah dan sayur di Pasar Anyar Singaraja tersebar di 17 Desa/Kelurahan dari 3 Kecamatan yang berada di Kabupaten Buleleng. Dari 17 Desa/Kelurahan tersebut tentunya memiliki jarak yang bervariasi, jarak terjauh berada di Desa Kubutambahan dan yang terdekat berada di Singaraja.

\section{PENUTUP}

Berdasarkan hasil penelitian dan pembahasan yang telah disajikan, maka dapat disimpulkan sebagai berikut. 1) Tingkat Fekuensi mobilitas memperlihatkan bahwa rata-rata dalam seminggu frekuensi mobilitas yang dilakuakan mencapai 6,4 kali dalam seminggu. Hal ini memperlihatkan bahwa fekunsi mobilitas yang dilakuakan cukup tinggi, selain itu karena tuntutan ekonomi untuk memenuhi kebutuhan dan sarana prasarana transportasi semakin memadai di Kota Singaraja. 2) Tingkat pendapatan pelaku mobilitas yaitu pedagang buah dan sayur di Anyar Singaraja dalam melakukan aktivitas mobilitas dalam tabulasi tersebut dapat diketahui bahwa penghasilan bersih terendah pelaku mobilitas adalah $\mathrm{Rp}$. 100.000 dan tertinggi Rp. 500.000 dalam 1 kali berdagang ditinjau dari UMR yang berlaku di tahun 2018 yaitu 2.165.000,00/ orang dalam satu bulan rata-rata memiliki penghasilan diatas UMR dan dapat tergolong dalam taraf hidup layak untuk di Kabupaten Buleleng. 3) Hubungan antara frekuensi mobilitas dengan tingkat pendapatan, melalui perhitungan menggunakan rumus korelasi product movement mendapatkan hasil frekuensi mobilitas berpengaruh negative (memiliki hubungan signifikan yang sangat rendah) terhadap pendapatan sebesar $(0,150)$, dengan kata lain frekuensi moilitas harian pedagang buah dan sayur di Pasar Anyar Singaraja tidak berhubungan dengan tinkat pendapatan pedagang.

Dari hasil pengamatan yang telah dilakukan, maka dapat disarankan hal - hal sebagai berikut : 1) Disarnkan kepada peneliti lain yang mengkaji penelitian sejenis untuk mencari lebih banyak teori-teori tentang mobilitas untuk meningkatkan wawasan dan informasi yang diperoleh lebih maksimal. 2) Disarankan kepada masayarakat yang melakukan kegiatan mobilitas agar lebih meningkatkan frekuensi mobilitas dan pengembangan produk yang dijual agar mencapai hasil yang maksimal 3) Disarankan kepada pemerintah agar lebih meningkatkan pelayanan terutama dibidang sarana dan prasarana serta fasilitas umum di kawasan Pasar Anyar Singaraja. 
Arikunto, Suharsini. 1993. Prosedur Penelitian

Suatu Pendekatan Praktis.

Jakarta: Rineka Cipta

Badan Pusat Statistik. 2016a. Kabupaten

Buleleng Dalam Angka 2011.

Singaraja : BPS Kabupaten

Buleleng

2017b. Kecamatan Buleleng Dalam Angka Dalam 2017.Singaraja:

BPS Kabupaten Buleleng

-2017c. Kecamatan Sawan Dalam Angka

Dalam 2017.Singaraja: BPS

Kabupaten Buleleng

-2017d. Kecamatan Sukasada Dalam Angka Dalam 2017.Singaraja: BPS Kabupaten Buleleng

Kawi, Gede. 1996. Buku ajar Mobilitas Penduduk. Sekolah Tinggi Keguruan dan IImu Pendidikan Negeri .Singaraja ( tidak diterbitkan ).

\section{DAFTAR PUSTAKA}

Anonim.2018. "Mobilitas Penduduk Sirkuler di Kota Cimahi" Tersedia Pada http://respository.upi.edu/operator/ upload/s geo 011762 chapter4.p df (diakses tanggal 8 Juni 2018)

Antari, sili, 2006. "Pengaruh Pendapatan, Pendidikan, dan Remitan Terhadap Pengeluaran Konsumsi Pekerja Migran Nonpermanen di Kabupaten Badung (Studi Kasus di Kabupaten Bandung)" Tersedia pada

http://ejournal.unud.ac.id/abstrak/ $6 \% 20$ naskah\%20sili.pdf (diakses tanggal 8 Juni 2018)
Kasto. 2002. Mobilitas Penduduk Dan Dampaknya Terhadap Pembangunan Daerah (Dalam Buku Mobilitas Penduduk Indonesia Tinjauan Lintas Disiplin). Yogyakarta : PSKK UGM

Lee, Everett S. 2000. Teori Migrasi (Seri Terjemahan No 3). Yogyakarta : PPK UGM

Mantra, Ida Bagus. 1997. Pengantar Studi Demografi. Yogyakarta: Nurcahya

------, 2000.Demografi Umum Edisi Kedua.

Yogyakarta : Pustaka Pelajar 
------, 2003. Demografi Umum. Pustaka

Pelajar: Yogyakarta

Munandar, M. 2001. Teori Pendapatan.

Yogyakarta: Nurcahya

Munir, R. 2007. Migrasi (Dalam Buku DasarDasar Demografi). Jakarta: Lembaga Penerbit FEUI

Pabundu, Tika. 2005. Metode Penelitian Geografi. Jakarta: Bumi Aksara

Peta Rupa Bumi Indonesia. 2000. Lembar 1707-631. Skala $1: 25.000$

Peta Rupa Bumi Indonesia. 2000. Lembar 1707-632. Skala $1: 25.000$

Peta Rupa Bumi Indonesia. 2000. Lembar 1707-633. Skala $1: 25.000$

Peta Rupa Bumi Indonesia. 2000. Lembar 1707-634. Skala $1: 25.000$

Pasar, Perusahaan.Daerah., 2016. Tabel Jumlah Pedagang Buah Di Pasar Anyar. Kabupaten Buleleng

Standing, Guy. 1991. Konsep-Konsep Mobilitas Di Negara Sedang Berkembang (Seri
Terjemahan No 24). Yogyakarta : PPK UGM

Sriartha, 2004. Dasar-Dasar Metodologi Penelitian Geografi. Institut Keguruan dan IImu Pendidikan Negeri Singaraja

Sugiono,2010. Statika Untuk Penelitian. Bandung : Alfabeta

Suryabrata, Sumadi. 2003. Metodologi Penelitian. Jakarta: Rajawali Pers

Todaro, Michael P. 1998. Pembangunan Ekonomi Di Dunia Ketiga. Jakarta: Erlangga 
